\title{
Effectiveness of Green Additives vs Poly(acrylic acid) in Inhibiting Calcium Sulfate Dihydrate Crystallization
}

\author{
Taher Rabizadeh, ${ }^{*}, \dagger \oplus$ David J. Morgan, ${ }^{\S \oplus}$ Caroline L. Peacock, ${ }^{\dagger}$ and Liane G. Benning, ${ }^{*},, \|, \perp$ \\ ${ }^{\dagger}$ School of Earth and Environment, University of Leeds, Leeds LS2 9JT, United Kingdom \\ ${ }^{\ddagger}$ Department of Materials Engineering, Faculty of Mechanical Engineering, University of Tabriz, 51666-16471 Tabriz, \\ Iran ${ }^{\S}$ Cardiff Catalysis Institute, School of Chemistry, Cardiff University, Cardiff CF10 3AT, United Kingdom \\ "GFZ, German Research Centre for Geosciences, Telegrafenberg, 14473 Potsdam, Germany \\ ${ }^{\perp}$ Department of Earth Sciences, Free University of Berlin, 12249 Berlin, Germany
}

ABSTRACT: The effects that 20 ppm poly(epoxysuccinic acid) (PESA), poly(aspartic acid) (PASP), and two poly(acrylic acid) (PAA) compounds with molecular weights of $\sim 2000$ and $\sim 100$ 000 have on the crystallization of gypsum were evaluated at $21^{\circ} \mathrm{C}$ by in situ UV-vis spectrophotometry. XRD and SEM were utilized for phase and morphological studies, while the way these additives are associated with the final gypsum crystals was evaluated by XPS. The comparison showed that PASP performed far better than the other antiscalants as it completely inhibited the formation of gypsum. In contrary, the presence of the low molecular weight PAA decreased the rate of crystallization far more than the larger molecular weight PAA. When the $\mathrm{pH}$ in the reacting solution was switched from $\sim 4$ to $\sim 7$, the efficiency of
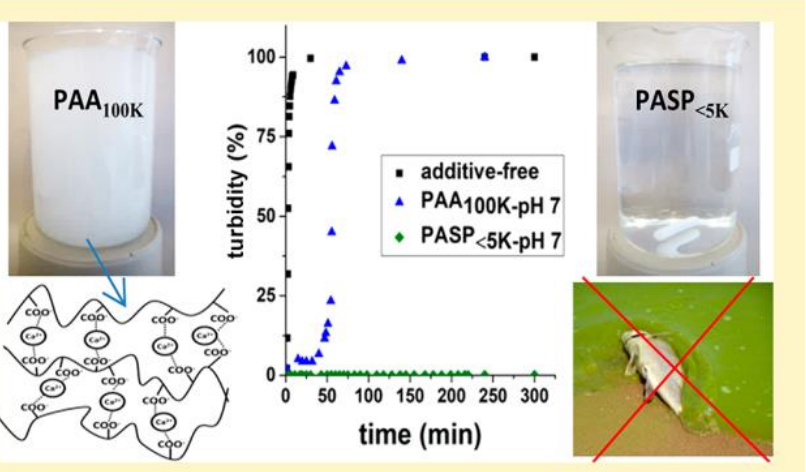
the

low molecular weight PAA in inhibiting gypsum formation increased, while in the presence of the higher molecular weight PAA the opposite effect was observed.

\section{INTRODUCTION}

In many industrial processes that rely on water handling systems (e.g., oil and gas production, water desalination, water treatment, cooling systems, etc.), the formation of mineral scales in pipes, filters, and heat exchangers has detrimental consequences to process efficiency. ${ }^{1}$ These include flow reduction, notable depression in the heat transfer efficiency, and clogging of pipes, valves, and other equipment, as well as other side effects such as corrosion which all result in efficiency losses. ${ }^{2,3}$ Common scale deposits are calcium carbonate, ${ }^{4}$ silica, ${ }^{5}$ barium sulfate, ${ }^{6}$ and calcium sulfate ${ }^{7}$ known as sparingly soluble crystals. In a large number of water handling processes, calcium sulfate scales form preferentially, and they are more stable than other scale types because their formation is $\mathrm{pH}$ independent (i.e., they can precipitate at $\mathrm{pH}$ as low as 2 ), ${ }^{8}$ and this leads to serious problems in many industrial water processing activities. ${ }^{9}$ Cleaning or removing mineral scales is costly, and they affect the efficiency and lifetime of processing technologies. ${ }^{10}$ It is, therefore, preferable to prevent scale formation rather than remove scale products. In the calcium sulfate system, three phases with various degrees of hydration exist: the dihydrate gypsum $\left(\mathrm{CaSO}_{4} \cdot 2 \mathrm{H}_{2} \mathrm{O}\right)$, the hemihydrate bassanite $\left(\mathrm{CaSO}_{4} \cdot 0.5 \mathrm{H}_{2} \mathrm{O}\right)$, and the anhydrous anhydrite $\left(\mathrm{CaSO}_{4}\right){ }^{11}$ As with many other sparingly soluble salts, temperature, supersaturation, and the presence of impurities affect the formation and solubility of the different polymorphs. 12

Various methods to inhibit, reduce, or prevent the formation of calcium sulfate scales have been proposed. Among them, the addition of inhibitors or antiscalants is the most economical and is more efficient than acid washing or mechanical cleaning. ${ }^{13,14}$ Antiscalants are generally divided into non-polymeric (e.g., hexametaphosphates, phosphonates) ${ }^{15}$ and polymeric (e.g., polycarboxylates), ${ }^{16}$ and their application and effects on mineral scaling have been extensively studied. ${ }^{2}$ It has been suggested that antiscalants can prevent scale formation by different ways, such as through sequestration or chelation of the ions in solution that are required for mineral precipitation, increasing the interfacial tension between nuclei and the solution, dispersing scale mineral crystallites, and/or adsorbing to the growing scale mineral surfaces. ${ }^{4}$ However, a molecular level understanding of the mechanisms by which antiscalants prevent mineral scaling is still lacking.

In addition, the postreaction disposal of such industrial inhibitors leads to pollution of the environment. ${ }^{17-19}$ For example, when such $\mathrm{P}$ and $\mathrm{N}$ containing compounds reach 
water ways, they play a key role in eutrophication which can cause major ecological damage. ${ }^{19}$ Therefore, the concept of "Green Chemistry" was proposed, and scale inhibitors that are not detrimental to our environment have become a recent focus for inhibiting industrial scale formation. ${ }^{20,21}$

Among green inhibitors, poly(epoxysuccinic acid) (PESA) and poly(aspartic acid) (PASP) are the most common and promising environmentally friendly polycarboxylate antiscalants. They are both highly biodegradable and nontoxic, ${ }^{22}$ two of the main criteria of a "green" inhibitor. PESA and PASP have both been extensively used in various industrial applications such as water treatment. ${ }^{23}$ However, to date, studies that evaluate the effects of different poly(carboxylic acid) inhibitors on gypsum precipitation have primarily focused on changes in precipitation onset, or the effect of high temperatures. $^{24-27}$ Therefore, a mechanistic under-standing of the effects that different poly(carboxylic acids), particularly the green ones, have on gypsum formation is still lacking. How these inhibitors operate, and how they can be optimized to inhibit scale formation, is poorly understood. Indeed, in some cases, it is still unclear whether the commonly used conventional less biodegradable polycarboxylic inhibitors (e.g., poly(acrylic acid)) can be replaced by greener equivalents (e.g., PESA and PASP).

To address these gaps in our knowledge, we present here results from a study on the effects of three common industrial poly(carboxylic acids) on the formation kinetics and phase morphologies of gypsum. We tested two green inhibitors (PESA and PASP) and two polyacrylic acids with different molecular weights (PAA; as common less green inhibitors) and derived a mechanistic understanding of the inhibition processes. We document important differences in the crystallization trends in the presence of the different inhibitors, and demonstrate that the additives adsorbed onto the surface of the newly forming gypsum crystals, and changed the shapes and sizes of the resulting crystals. We also demonstrate the significant impact of the molecular weight of polymeric antiscalants on gypsum inhibition efficiencies and illustrate the potential of PESA and PASP as a suitable replacement for the environmentally unfriendly PAA antiscalant to prevent gypsum formation.

\section{EXPERIMENTAL METHODS}

Gypsum crystallization solutions were produced by mixing equal volumes of a $200 \mathrm{mM} \mathrm{CaCl} 2 \cdot 2 \mathrm{H}_{2} \mathrm{O}$ solution $(100 \%$ AnalaR Normapour VWR) and a $200 \mathrm{mM} \mathrm{Na} 2 \mathrm{SO}_{4}$ solution (100\% AnalaR Normapour VWR) in a $1 \mathrm{~L}$ reactor at room temperature $\left(21{ }^{\circ} \mathrm{C}\right)$ and under constant and continuous stirring. After mixing, an additive-free gypsum crystallization solution with a supersaturation index of 0.84 calculated with the geochemical computer code PhreeqC 3.3.3 was obtained. ${ }^{28}$ Polyepoxysuccinic acid sodium salt $\left(40 \mathrm{wt} \%\right.$ in $\left.\mathrm{H}_{2} \mathrm{O}\right)$ with

$\mathrm{M}_{\mathrm{W}} \sim 400-1500 \mathrm{Da}(\mathrm{PESA}<1.5 \mathrm{~K})$, polyaspartic acid sodium salt (40 wt \% in $\mathrm{H}_{2} \mathrm{O}$ ) with $\mathrm{M}_{\mathrm{w}} \sim 1000-5000 \mathrm{Da}(\mathrm{PASP}<5 \mathrm{~K})$, provided by Shandong Taihe Water Treatment Technologies Company, and two polyacrylic acids (Sigma-Aldrich) with $\mathrm{M}_{\mathrm{w}}$

$\sim 2000 \mathrm{Da}\left(\mathrm{PAA}_{2 \mathrm{~K}} ; 63\right.$ wt $\%$ in $\left.\mathrm{H}_{2} \mathrm{O}\right)$ and $\sim 100000 \mathrm{Da}$ ( $\mathrm{PAA}_{100 \mathrm{~K}} ; 35$ wt $\%$ in $\mathrm{H}_{2} \mathrm{O}$ ) were added to the initial sodium sulfate solution at a concentration of $40 \mathrm{ppm}$. This was done prior to mixing of this stock solution with the calcium chloride stock solution. Therefore, once mixed the solutions contained $100 \mathrm{mM} \mathrm{Ca}^{2+}, 100 \mathrm{mM} \mathrm{SO}_{4}{ }^{2-}$, and $20 \mathrm{ppm}$ additive. In all experiments, the $\mathrm{pH}$ of the mixed solutions was adjusted to $\sim 4$ or $\sim 7$, with $\mathrm{NaOH}$ and/or $\mathrm{HCl}$.

Changes in the mixed solutions were monitored by measuring the increase in absorbance using a UV-vis spectrophotometer (Uvikon XL) at $\lambda=520 \mathrm{~nm}$ with the angle between the incident beam and detector of $180^{\circ}$. The reactions were followed at room temperature for up to 300 min by measuring the absorbance of $3 \mathrm{~mL}$ aliquots taken from the mixed solutions. Each experimental set was carried out in triplicate. The absorbance data are plotted as the normalized change in solution turbidity over time.

At the end of each experiment, the solutions were quenchfiltered $(0.2 \mu \mathrm{m})$ under vacuum and the solids retrieved. In all experiments, regardless if additives were present or not, the solid end-products were always gypsum as determined by powder X-ray diffraction (XRD; Bruker D8 diffractometer; $\mathrm{Cu}$ $\mathrm{Ka}_{1} ; 2 \theta$ range $5-35^{\circ}$; resolution $0.105^{\circ} /$ step; counting time 1 s/step) with XRD patterns analyzed with the EVA software (version 3) and the PDF-2-1996 database. The morphology of the formed gypsum crystals was imaged using a field emission gun scanning electron microscope (FEG-SEM, FEI Quanta $650,5 \mathrm{kV})$. The sizes and shapes of the resulting crystals were evaluated using ImageJ v. 1.49 software. $^{29}$

Finally, to determine the nature of the surface interactions between the inhibitors and the gypsum end-products, we employed X-ray photoelectron spectroscopy (XPS) with a detection limit of 0.1 atom \% (which is roughly 1 parts per thousand (ppth) or $10^{19}$ atoms $/ \mathrm{cm}^{3}$ ). XPS spectra were acquired from the top 8-10 nm of gypsum crystals using a Kratos Axis Ultra-DLD spectrometer with a monochromatic Al Ka X-ray source $(144 \mathrm{~W})$ and analyzer pass energies of $40 \mathrm{eV}$ (high resolution scans). The base pressure during analysis was ca. $6 \times$ $10^{-7} \mathrm{~Pa}$. All data were referenced to the $\mathrm{C}$ 1s signal at $284.8 \mathrm{eV}$ and quantified using CasaXPS (Version 2.3.15) using elemental sensitivity factors supplied by the manufacturer.

\section{RESULTS}

In the additive-free experiments at both $\mathrm{pH}$ values tested $(\sim 4$ or $\sim 7$ ), the solutions became turbid after $\sim 30$ s (called induction time). Following crystallization induction, it took $\sim 30$ min for the solutions to reach 100\% turbidity (Figure 1, black data points). However, the addition of the inhibitors at $\mathrm{pH} \sim 7$ affected the induction times and the time to reach a

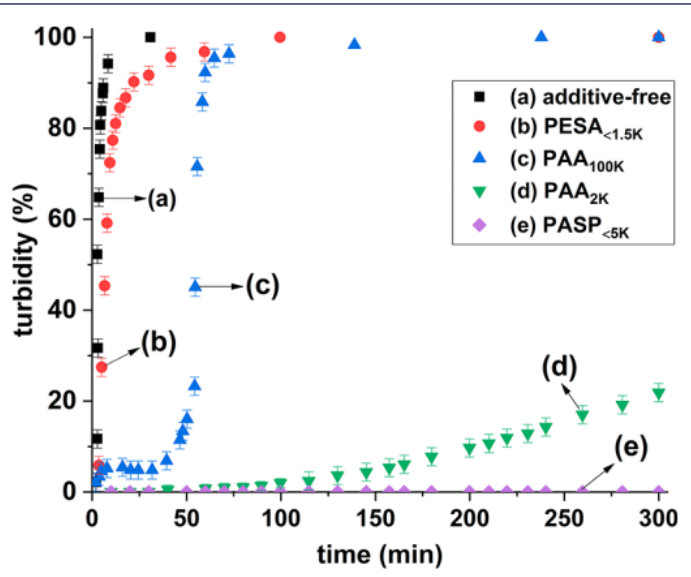

Figure 1. Effect of adding $20 \mathrm{ppm} \mathrm{PESA}_{<1.5 \mathrm{~K}}, \mathrm{PAA}_{100 \mathrm{~K}}, \mathrm{PAA}_{2 \mathrm{~K}}$, or $\mathrm{PASP}<5 \mathrm{~K}$ at $\mathrm{pH} \sim 7$ on the development of solution turbidity compared to the additive-free gypsum crystallization. 
maximum turbidity plateau. In the presence of PESA $<1.5 \mathrm{~K}$, the induction time increased $\sim 3$ fold (to $\sim 90 \mathrm{~s}$ ), and it took $\sim 90$ min to reach $100 \%$ turbidity (Figure 1 , red data points). In contrast, the presence of PAA $100 \mathrm{~K}$ actually accelerated the onset of turbidity, with the first turbidity appearing after $\sim 10 \mathrm{~s}$. However, after this initial onset only a small increase in total turbidity $(\sim 5 \%)$ was reached, and subsequently the turbidity remained suppressed up to $\sim 40 \mathrm{~min}$. Only in a second stage did the turbidity start to increase sharply again reaching $100 \%$ within the following $\sim 30 \mathrm{~min}$. The slope of the turbidity increase in this stage was similar to the slope of the turbidity development in the additive-free solution (Figure 1, blue data points). In the presence of the lower molecular weight additive, $\mathrm{PAA}_{2 \mathrm{~K}}$, a dramatic increase in the induction time ( $\sim 80$ fold, to $\sim 40 \mathrm{~min}$ ) was observed, and the slope of the turbidity curve also decreased. The turbidity continued to only gradually increase, and it only reached $\sim 20 \%$ of the maximum possible turbidity even after $300 \mathrm{~min}$ (Figure 1, olive data points). However, the most noticeable effect was observed in the presence of $\mathrm{PASP}<5 \mathrm{~K}$, where no changes in turbidity were measured even after $300 \mathrm{~min}$ (Figure 1, lavender data points). The overall order for inhibition effectiveness was therefore $\mathrm{PESA}<1.5 \mathrm{~K}<\mathrm{PAA}_{100 \mathrm{~K}}<\mathrm{PAA} 2 \mathrm{~K}<\mathrm{PASP}<5 \mathrm{~K}$.

The effects of PAA $100 \mathrm{~K}$ and $\mathrm{PAA}_{2 \mathrm{~K}}$ on the onset and the development of turbidity also exhibited a $\mathrm{pH}$-dependence (Figure 2). At $\mathrm{pH} \sim 4$, with $\mathrm{PAA}_{100 \mathrm{~K}}$, the onset of turbidity was

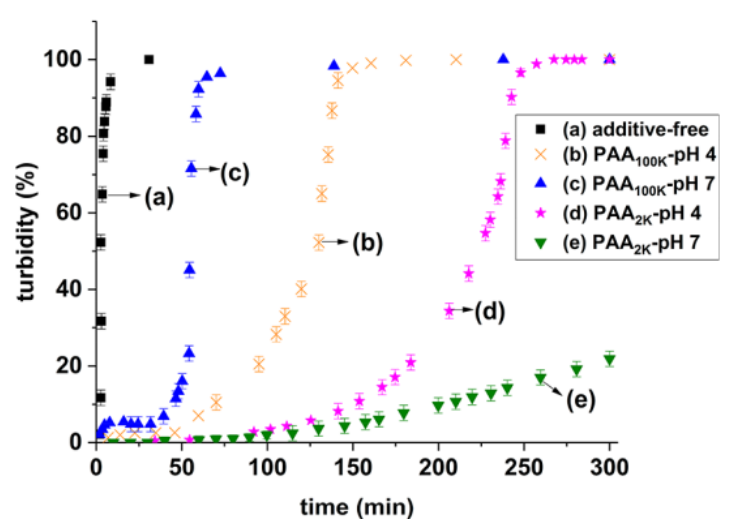

Figure 2. Effect of $20 \mathrm{ppm} \mathrm{PAA}_{2 \mathrm{~K}}$ and $\mathrm{PAA}_{100 \mathrm{~K}}$ on the development of turbidity at $\mathrm{pH} \sim 4$ and $\sim 7$. Note that in the additive-free system the turbidity development was equally fast at $\mathrm{pH} \sim 4$ or $\sim 7$, and thus both are represented by the black squares.

almost the same as that in the additive-free system ( 30 s). However, the subsequent development of the turbidity was slower and followed a different trend than the additive-free and PAA $100 \mathrm{~K}$ at $\mathrm{pH} \sim 7$ systems (Figure 2, black vs blue vs orange data points). Specifically, at $\mathrm{pH} \sim 4$ the turbidity remained at a constant $\sim 2 \%$ for $\sim 50 \mathrm{~min}$, and for the next $\sim 80$ min the turbidity only increased slowly and exponentially until reaching $\sim 50 \%$. After this point $(\sim 130 \mathrm{~min})$, the turbidity abruptly increased and reached a plateau within the next $\sim 10 \min (\sim 140 \mathrm{~min}$ after onset) with a slope similar to the slope of the turbidity development in the additive-free system. This clearly

documents that $\mathrm{PAA}_{100 \mathrm{~K}}$ is a more effective inhibitor at $\mathrm{pH}$ $\sim 4$ than at $\sim 7$. On the other hand, for $\mathrm{PAA}_{2 \mathrm{~K}}$ at $\mathrm{pH} \sim 4$ the first

change in turbidity was measured after $\sim 25 \mathrm{~min}$ (in contrary to the induction time of $\sim 40 \mathrm{~min}$ at $\mathrm{pH} \sim 7$ ), and for the next $\sim 210 \mathrm{~min}$ the turbidity increased exponentially until reaching $\sim 60 \%$. In a final stage, the turbidity then sharply increased and leveled off after $\sim 255$ min with a slope similar to the slope of the turbidity development in the additive-free system (Figure 2, magenta data points). These results indicate that $\mathrm{PAA}_{2} \mathrm{~K}$ is a more effective inhibitor at $\mathrm{pH} \sim 7$.

To obtain further insights into the role of the additives in inhibiting gypsum crystallization, the atomic compositions of the topmost surface layers of the gypsum crystals precipitated in the absence and presence of the additives were characterized by XPS (Table 1). In this table Ca 2p, S 2p, and O 1s represent

Table 1. Surface Composition of the Precipitated Gypsum Crystals As Analyzed by XPS (atom \%) ${ }^{\mathrm{a}}$

\begin{tabular}{|c|c|c|c|c|c|}
\hline & $\mathrm{O} 1 \mathrm{~s}$ & $\mathrm{C} 1 \mathrm{~s}$ & $\mathrm{Ca} 2 \mathrm{p}$ & $S 2 p$ & $\mathrm{Na} 1 \mathrm{~s}$ \\
\hline additive-free & 58.6 & 14.7 & 12.8 & 13.7 & 0.2 \\
\hline $\mathrm{PESA}<1.5 \mathrm{~K}-\mathrm{pH} \sim 7$ & 61.1 & 14.9 & 11.7 & 12.1 & 0.2 \\
\hline $\mathrm{PAA}_{2 \mathrm{~K}}-\mathrm{pH} \sim 4$ & 53.9 & 23.8 & 10.8 & 11.3 & 0.2 \\
\hline $\mathrm{PAA}_{2 \mathrm{~K}-\mathrm{pH} \sim 7}$ & 52.5 & 25.7 & 11.1 & 10.5 & 0.2 \\
\hline $\mathrm{PAA}_{100 \mathrm{~K}}-\mathrm{pH} \sim 4$ & 57.9 & 16.6 & 12.4 & 12.9 & 0.2 \\
\hline $\mathrm{PAA}_{100 \mathrm{~K}-\mathrm{pH}} \sim 7$ & 58.2 & 15.1 & 12.8 & 13.7 & 0.2 \\
\hline
\end{tabular}

the atomic percent of these elements in the synthesized gypsum structure. The observed $\mathrm{Na} 1 \mathrm{~s}$ was due to the presence of $\mathrm{Na}^{+}$in the crystallization solution, while $\mathrm{C} 1$ s originates from the adventitious carbon and/or adsorbed carboxylate functional groups related to the tested antiscalants.

In addition, the $\mathrm{C} 1 \mathrm{~s}$ envelope was decomposed into three distinct peaks of $\mathrm{C} \mathrm{C}, \mathrm{C} \mathrm{O} \mathrm{C}$, and $\mathrm{O} \mathrm{C} \mathrm{O}$ groups. Table 2 presents the peak areas of $\mathrm{C} \mathrm{C}, \mathrm{C} \mathrm{O} \mathrm{C}$, and $\mathrm{O}$

Table 2. Peak Areas of C C, C O C, and O C O Functional Groups That Contributed to the Total C 1s Peak Area in the XPS Spectra on the Precipitated Gypsum Crystals ${ }^{a}$

\begin{tabular}{|c|c|c|c|c|}
\hline \multicolumn{3}{|c|}{$\mathrm{CC} \mathrm{COC}$} & \multirow{2}{*}{$\begin{array}{c}\mathrm{O} \text { C O } \\
8.08\end{array}$} & \multirow{2}{*}{$\begin{array}{c}\mathrm{R}_{(\mathrm{O} \mathrm{C} \mathrm{O} / \mathrm{C} \mathrm{C})} \\
0.10\end{array}$} \\
\hline additive-free & 79.77 & 12.16 & & \\
\hline $\mathrm{PESA}<1.5 \mathrm{~K}-\mathrm{pH} \sim 7$ & 72.75 & 18.75 & 8.51 & 0.11 \\
\hline $\mathrm{PAA}_{2 \mathrm{~K}}-\mathrm{pH} \sim 4$ & 66.48 & 15.49 & 18.03 & 0.27 \\
\hline $\mathrm{PAA}_{2 \mathrm{~K}}-\mathrm{pH} \sim 7$ & 45.4 & 36.47 & 18.33 & 0.40 \\
\hline PAA $100 \mathrm{~K}-\mathrm{pH} \sim 4$ & 72.71 & 13.22 & 14.07 & 0.19 \\
\hline $\mathrm{PAA}_{100 \mathrm{~K}}-\mathrm{pH} \sim 7$ & 80.9 & 10.4 & 8.69 & 0.13 \\
\hline
\end{tabular}

${ }^{\mathrm{a}}$ Note that no gypsum crystals precipitated from solutions containing $20 \mathrm{ppm}$ PASP $<5 \mathrm{~K}$ at $\mathrm{pH} \sim 7$.

C O functional groups, which contributed to the total $\mathrm{C} 1 \mathrm{~s}$ peak area. Besides the absolute peak area values, the variations in the peak area of $\mathrm{O} \mathrm{C} \mathrm{O}$ functional groups adsorbed on gypsum crystals with respect to the changes in the peak area of $\mathrm{C} \mathrm{C}$ were also expressed as O C O/C C peak area ratios $\left(\mathrm{R}_{(\mathrm{O} C}\right.$ $\mathrm{O} / \mathrm{C} \mathrm{C})$ ). As an example, the $\mathrm{C} 1 \mathrm{~s}$ XPS spectra for the additivefree and $\mathrm{PAA}_{2 \mathrm{~K}}$ adsorbed gypsum crystals produced at $\mathrm{pH} \sim 7$ are shown in Figure 3. The results in this figure reveal that in the additive-free sample two main functional groups $\mathrm{C} \mathrm{C}$ at $284.7 \mathrm{eV}$ and C O C at $286.3 \mathrm{eV}$, with only a trace amount of $\mathrm{O} \mathrm{C} \mathrm{O}$ at $288.93 \mathrm{eV}$, are present. In contrast, in the PAA amended sample, although

$2 \mathrm{~K}$

the same two functional groups $\mathrm{C} \mathrm{C}$ at $284.6 \mathrm{eV}$ and $\mathrm{C} \mathrm{O} \mathrm{C}$ at $285.5 \mathrm{eV}$ were observed, we also observed clear O C O moieties at $288.3 \mathrm{eV}$. 


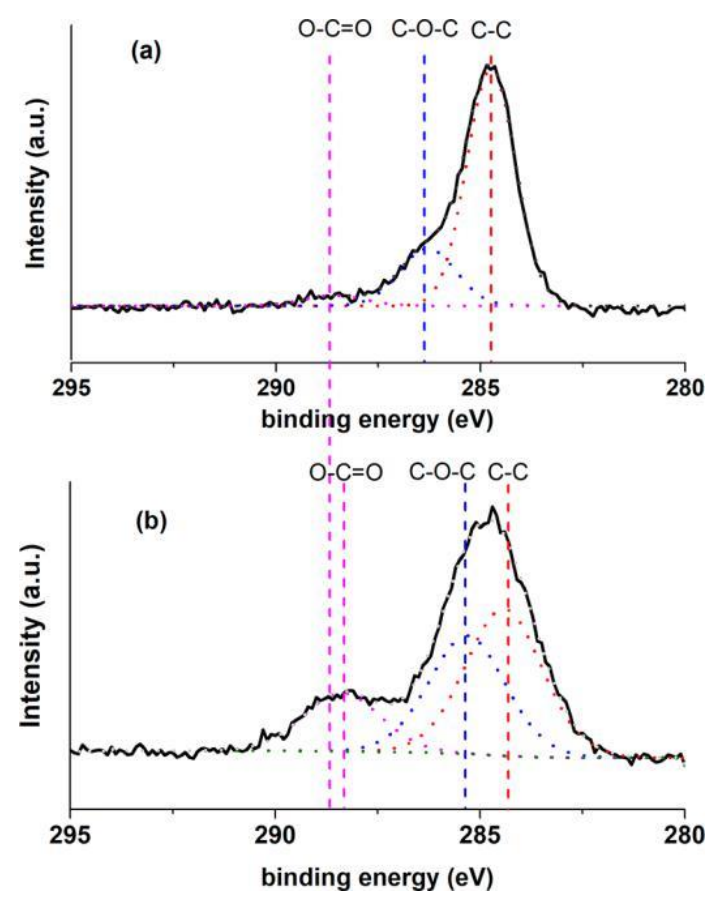

Figure 3. XPS spectra of C 1 s related to the end-product (after 300 min) gypsum crystals from (a) additive-free and (b) $20 \mathrm{ppm}$ PAA2K experiments at $\mathrm{pH} \sim 7$; the individual contributions to the fitted envelope of different functional groups are represented with dotted lines.

It is also worth noting that in Figure 4 the $\mathrm{Ca} 2 \mathrm{p}$ peaks corresponding to calcium ions in the gypsum structure from the additive-free and $\mathrm{PAA}_{2 \mathrm{~K}}$ amended experiments appeared at 347.45 and $346.65 \mathrm{eV}$, respectively.

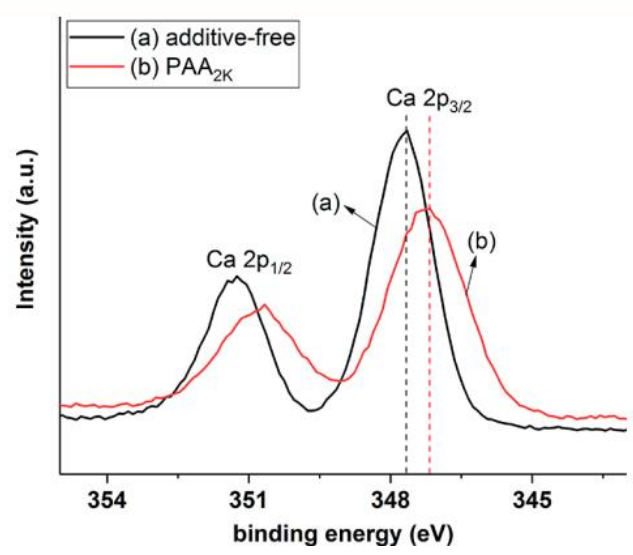

Figure 4. XPS spectra of Ca related to the gypsum end-product (after $300 \mathrm{~min}$ ) from (a) additive-free and (b) $20 \mathrm{ppm}$ PAA2K experiments at $\mathrm{pH} \sim 7$.

Morphological changes in the formed gypsum crystals in all experiments were characterized by SEM (Figure 5). The gypsum crystals that formed in the additive-free system and in the presence of $20 \mathrm{ppm} \mathrm{PESA}_{<1.5 \mathrm{~K}}$ and $\mathrm{PAA}_{100 \mathrm{~K}}$ at $\mathrm{pH} \sim 7$ were mostly large and thin twin crystals (Figure 5a,b,d). In contrast, adding 20 ppm of $\mathrm{PAA}_{100 \mathrm{~K}}$ at $\mathrm{pH} \sim 4$ modified the morphology of the gypsum crystals into relatively thick and twinned particles (Figure 5c). The most profound effect on gypsum morphology and size was observed when $\mathrm{PAA}_{2 \mathrm{~K}}$ was used as an inhibitor. At $\mathrm{pH} \sim 4$, small irregular gypsum crystals together with some blocky particles of sizes ranging between 2 and $10 \mu \mathrm{m}$ were precipitated (Figure 5e), and in stark contrast at $\mathrm{pH} \sim 7$, loose, tiny crystals with a size range from $20 \mathrm{~nm}$ to $5 \mu \mathrm{m}$ were observed (Figure $5 \mathrm{f}$ ).

\section{DISCUSSION}

Measuring turbidity and estimating induction times in the absence and presence of additives is one of the most common methods of evaluating the efficiency of antiscalants in delaying the nucleation and growth of sparingly soluble scale minerals and classifying them as "nucleating" and/or "growth" inhibitors. ${ }^{1}$ Our turbidity measurements (Figure 1) revealed that, at equal concentrations of $20 \mathrm{ppm}$ and up to $300 \mathrm{~min}$ of reaction, among the four polymers tested, $\operatorname{PASP}<5 \mathrm{~K}$ fully inhibited gypsum formation (no turbidity occurred). Thus, $\mathrm{PASP}<5 \mathrm{~K}$ is inherently a better gypsum crystallization inhibitor and can be considered a nucleating inhibitor, while, in the presence of PESA and the two PAA additives, gypsum crystals nucleated and grew with different growth rates which was reflected in the slope of the turbidity graphs. Hence, $\mathrm{PESA}<1.5 \mathrm{~K}$ and PAA are classified as growth inhibitors. However, this classification is not absolute and depends on the concentration of the inhibitors or the experimental conditions (e.g., temperature).

Furthermore, in this study (Figures 1 and 2) we have observed the development of turbidity curves that dramatically differ to those in our previous studies where we used carboxylic acid or inorganic inhibitors as additives. $^{30,31}$ The observed change in turbidity development likely stems from the differences in the nature of the additives and the mechanisms by which they affected the gypsum crystallization process. Parameters that can affect these inhibition reactions are naturally linked to the inhibition mechanism (e.g., surface adsorption), the factors governing the effectiveness of the polymeric additives (e.g., type and conformation of active functional groups, the molecular structure, and molecular weight of the polyelectrolytes), and the $\mathrm{pH}$ of the reacting solutions.

We have previously shown that $\mathrm{pH}$ is a main factor controlling the effectiveness of polycarboxylic additives in inhibiting gypsum crystallization because the speciation of the carboxylic groups is highly $\mathrm{pH}$ dependent. ${ }^{29}$ Considering the $\mathrm{pK}$ values for the tested additives $\left(\mathrm{PASP}<5 \mathrm{~K}, \mathrm{pK} 3.25,4.25 ;^{32}\right.$ $\mathrm{PESA}_{<1.5 \mathrm{~K}}$, pK 4.68, 4.92; ${ }^{33}$ PAA, pK $4.9{ }^{34}$ ) at higher $\mathrm{pH}$ (e.g., $\sim 7$ ), a greater number of deprotonated carboxylic groups are available in the solution to inhibit gypsum formation. Although sequestration or chelation of cations by $\mathrm{COO}^{-}$ functional groups has been suggested elsewhere, ${ }^{35,36}$ we assert that, due to the very low concentration of the antiscalants tested in this research, the inhibition process mainly occurred through surface adsorption. ${ }^{37}$

Besides deprotonation, the solution $\mathrm{pH}$ also affects the conformation of polymeric additives (see schematic illustration in Figure 6). For example, PAA is a weak polyelectrolyte, and its structure is $\mathrm{pH}$-responsive and undergoes $\mathrm{pH}$ dependent conformational changes. Upon addition of PAA to a crystallization solution, due to extensive intermolecular hydrogen bonding, an acidic solution of polymers with a highly coiled structure is produced. With increasing $\mathrm{pH}$, the carboxylic groups are deprotonated, and a high amount of negative charge densities are produced; the polymer chains become extended as a result of electrostatic repulsion. ${ }^{38}$ These extended polymer chains are better able to complex with $\mathrm{Ca}^{2+}$ 


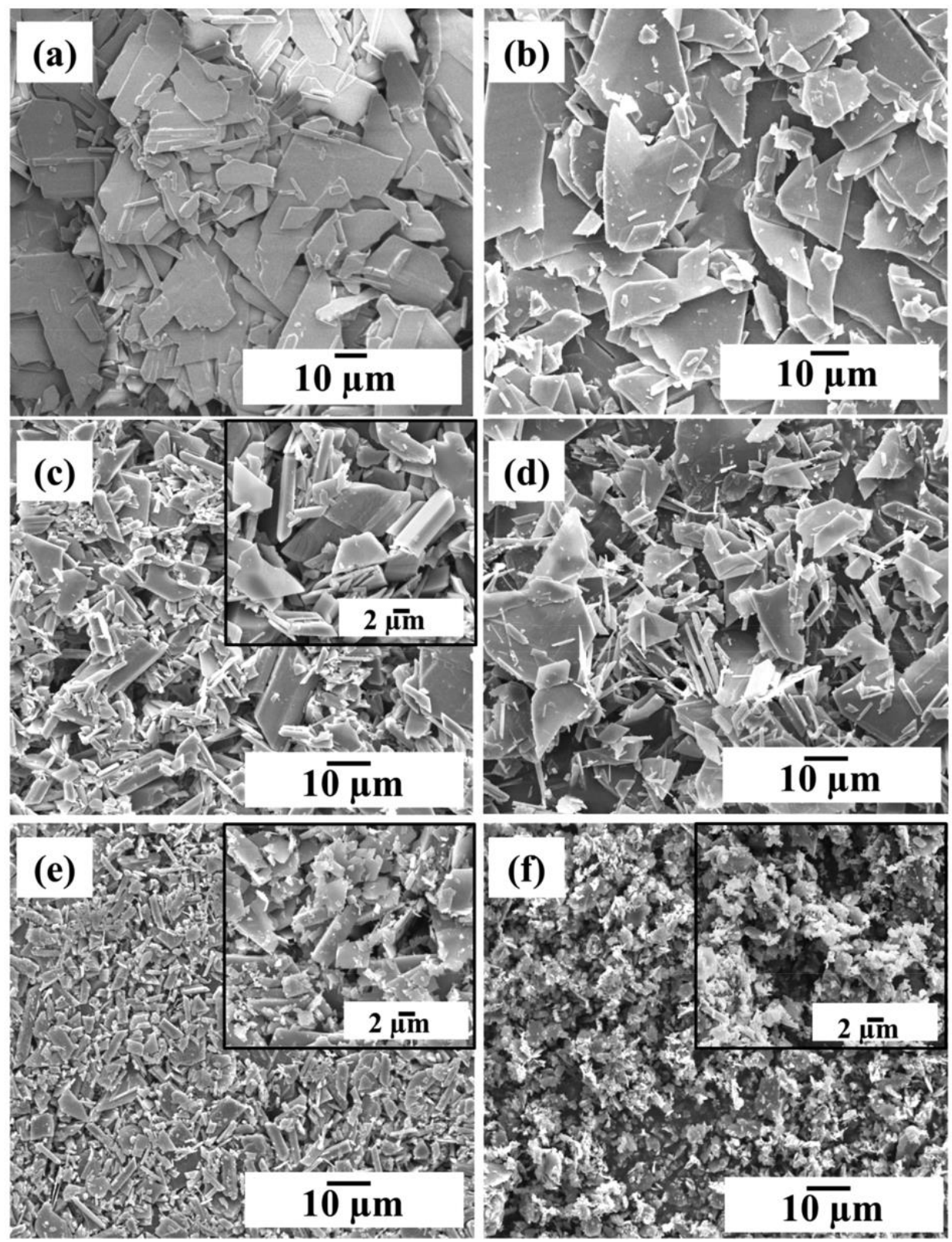

Figure 5. SEM micrographs of gypsum crystals collected after $300 \mathrm{~min}$ in experiments that were (a) additive-free at $\mathrm{pH} \sim 7$, (b) $20 \mathrm{ppm}$ PESA $<1.5 \mathrm{~K}$ at $\mathrm{pH} \sim 7$, (c) $20 \mathrm{ppm}$ PAA $100 \mathrm{~K}$ at $\mathrm{pH} \sim 4$, (d) $20 \mathrm{ppm}$ PAA $100 \mathrm{~K}$ at $\mathrm{pH} \sim 7$, (e) $20 \mathrm{ppm}$ PAA2K at pH 4, and (f) $20 \mathrm{ppm}$ $\mathrm{PAA}_{2 \mathrm{~K}}$ at $\mathrm{pH} \sim 7$; note that no gypsum crystals precipitated from solutions containing $20 \mathrm{ppm}$ PASP $<5 \mathrm{~K}$ at $\mathrm{pH} \sim 7$ (see Figure 1).

in solution or on the crystal surfaces (stronger surface adsorption). In our current study, when $\mathrm{PAA}_{2 \mathrm{~K}}$ is used, an increase in $\mathrm{pH}$ from $\sim 4$ to $\sim 7$ led to the extended monomers being uniformly distributed in solution, and this dramatically inhibited gypsum formation (Figure 2). Indeed, this feature of PAA has been successfully exploited to disperse nanoparticles (e.g., carbon nanotube) at high $\mathrm{pH}^{39}$

In contrast, for the higher molecular weight compound, PAA $100 \mathrm{~K}$, increasing the $\mathrm{pH}$ from $\sim 4$ to $\sim 7$ led to a faster gypsum formation reaction and less inhibition (Figure 2). This highlights the role of molecular weight of the polymers (which governs the number and conformation of the carboxylic groups) in determining the effectiveness of the inhibitors as well. We assert that at $\mathrm{pH} \sim 7$, upon mixing the sulfate solution containing $\mathrm{PAA}_{100 \mathrm{~K}}$ with the calcium solution, due to very high molecular weight and short distances between the monomers, available $\mathrm{Ca}^{2+}$ ions cross-linked the extended $\mathrm{PAA}_{100 \mathrm{~K}}$ polymer chains to each other and built a "netlike" structure which decreased the efficiency of the inhibitor. This made the solution immediately turbid (see $~ 5 \%$ turbidity; blue points in Figure 2) and prevented the polymer adsorbing to the nucleating and growing crystals. As a result, by losing the efficiency of the inhibitor, gypsum crystals could easily nucleate and grow (due to the excess of sulfate and $\mathrm{Ca}^{2+}$ ions not affected by the forming "net-structure"). However, at $\mathrm{pH} \sim 4, \mathrm{PAA}_{100 \mathrm{~K}}$ was slightly deprotonated and is present as an almost coiled configuration; therefore $\mathrm{Ca}^{2+}$ ions could partially build a "net-structure" (see $~ 2 \%$ turbidity; orange points in Figure 2),

and thus most of the coiled PAA $100 \mathrm{~K}$ could adsorb onto the nucleating and growing gypsum crystals. Therefore, PAA $100 \mathrm{~K}$ yielded higher inhibitory effect at $\mathrm{pH} \sim 4$ than $\mathrm{pH} \sim 7$. Indeed, the role of $\mathrm{Ca}^{2+}$ in cross-linking PAA polymers and alginates 


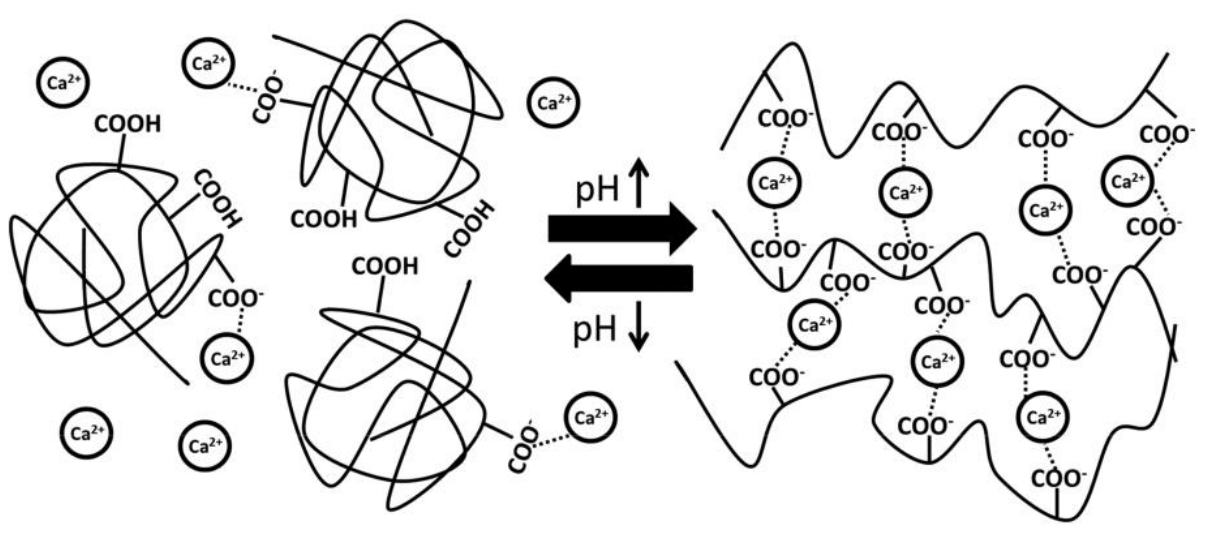

(a)

(b)

Figure 6. Schematic illustration of the effect of $\mathrm{pH}$ on the conformation of $\mathrm{PAA}_{100 \mathrm{~K}}$ : (a) $\mathrm{PAA}_{100 \mathrm{~K}}$ molecules at $\mathrm{pH} \sim 4$ are only minimally deprotonated and randomly coiled. (b) At $\mathrm{pH} \sim 7$ despite being deprotonated and in their extended conformation, $\mathrm{PAA}_{100 \mathrm{~K}}$ molecules form a "netstructure" in the presence of $\mathrm{Ca}^{2+}$. This prevents further $\mathrm{Ca}^{2+}$ complexation and attachment of the PAA $100 \mathrm{~K}$ molecules to the crystal surfaces.

and forming a netlike structure (hydrogels) has been reported also for calcium carbonates. 40,41

Comparing the efficiency of $\mathrm{PAA}_{100 \mathrm{~K}}$ with $\mathrm{PAA}_{2 \mathrm{~K}}$ at constant $\mathrm{pH}$ of $\sim 4$ reveals the effects that molecular size of a polymeric inhibitor has on its antiscaling efficiency. In this research, $\mathrm{PAA}_{2 \mathrm{~K}}$ with small molecular chains desorbed too rapidly on gypsum crystals and therefore was more effective than PAA $_{100 K}$ which due to longer molecules could not rearrange on the formed crystallite surfaces and wasted most of its mass in trailing ends and loops (Figure 2). In other words, it might become more difficult for PAA $100 \mathrm{~K}$ to stretch its polymer chains into an extended configuration ${ }^{42}$ which is necessary to adsorb to the crystal surface and thus inhibit crystallization. ${ }^{27,43}$

It is also worth mentioning that the abrupt increase in turbidity in the presence of $\mathrm{PAA}_{2 \mathrm{~K}}$ at $\mathrm{pH} \sim 4$ (Figure 2;

turbidity of $\sim 60 \% ; \sim 235 \mathrm{~min}$ ) and $\mathrm{PAA}_{100 \mathrm{~K}}$ at $\mathrm{pH} \sim 4$ (Figure 2 ; turbidity of $\sim 50 \%$; $130 \mathrm{~min}$ ) could be attributed to a depletion of the inhibitors from the reacting solution due to surface adsorption during gypsum growth. That means that, as the turbidity increased in the mixing solution, nucleation and growth of new particles occurred, and the carboxylic functional groups strongly bonded onto the new surfaces; therefore their concentration gradually decreased in solution. This continued until at a certain point where bulk gypsum crystals easily nucleated and grew, as made evident by the abrupt increase in turbidity with a slope similar to the additive-free system (Figure 2).

This surface adsorption is irreversible because calcium ions in the gypsum structure have a high hydration energy and are highly shielded by structural water molecules and/or the surrounding solution. $^{44}$ On the other hand, gypsum has negative surface charge above $\mathrm{pH} \sim 2$, and this implies that surface adsorption of the studied additives should not happen easily. ${ }^{45}$ However, taken together these lines of evidence indicate that the carboxylic functional groups in our used additives did not adsorb onto the gypsum crystals via classical electrostatic interaction (physisorption), but their adsorption occurred through chemisorption. This likely occurred through a "ligand-exchange" mechanism (also known as "specific adsorption" or "coordination adsorption"), during which the carboxylic functional groups replaced the hydroxyl groups linked to the $\mathrm{Ca}^{2+}$ ions. ${ }^{46}$ Similarly, the adsorption of anions onto other hydrated minerals (e.g., $\alpha$-alumina) ${ }^{47}$ via ligand-exchange mechanism has been documented.
Considering the mechanisms discussed above, PASP $<5 \mathrm{~K}$ inhibited gypsum formation most effectively due to the presence of high numbers of deprotonated $\mathrm{COO}^{-}$functional groups in the $\mathrm{PASP}<5 \mathrm{~K}$ monomer. This enabled $\mathrm{PASP}<5 \mathrm{~K}$ to adsorb strongly onto gypsum crystals. In addition, unlike PAA $100 \mathrm{~K}$, the tested PASP $<5 \mathrm{~K}$ had a molecular weight of 1000-5000 Da; therefore $\mathrm{Ca}^{2+}$ ions did not cross-link the $\mathrm{PASP}<5 \mathrm{~K}$ polymer chains and did not lead to the formation of a "netlike" structure.

Our assertion that surface adsorption plays a major role is supported by our XPS analysis which confirmed the surface adsorption of the additives. The variation in $\mathrm{C} 1 \mathrm{~s}$ chemical states, especially comparing the $\mathrm{O} \mathrm{C}=\mathrm{O}$ binding energy, its peak area, and $\mathrm{O} \mathrm{C} \mathrm{O} / \mathrm{C} \mathrm{C}$ peak area ratio (Tables 1 and 2; Figure 3) with the additive-free gypsum crystals, helped us to assess the association between the polymers and the surface of gypsum crystals. ${ }^{4-50}$ In the absence of additive, the atomic percent of the adventitious carbon contamination ${ }^{51}$ was $\sim 14.7$ atom \%. This peak was composed of $\mathrm{C} \mathrm{C}, \mathrm{C} \mathrm{O} \mathrm{C}$, and $\mathrm{O} \mathrm{C} \mathrm{O}$ groups with peak areas of $\sim 79.77 \%, \sim 12.16 \%$, and $\sim 8.08 \%$, respectively. The $\mathrm{R}_{(\mathrm{O} \mathrm{C} \mathrm{O} / \mathrm{C} \mathrm{C})}$ in the additive-free system was $\sim 0.10$. In the PESA - $\mathrm{pH} \sim 7$ system, a minor

increase in $\mathrm{C} 1 \mathrm{~s}$ atom $\%$ to $\sim 14.9$ (with $\mathrm{O} \quad \mathrm{C} \quad \mathrm{O}$ peak area and $\mathrm{R}_{(\mathrm{O} \mathrm{C} \mathrm{O} / \mathrm{C} \mathrm{C})}$ of $\sim 8.51 \%$ and 0.11 , respectively) was observed indicating a very low adsorption affinity of $\mathrm{PESA}_{<1.5 \mathrm{~K}}$ onto the gypsum crystals. This corroborates our turbidity measurements (Figures 1 and 2) and demonstrates that deprotonated $\mathrm{PESA}<1.5 \mathrm{~K}$, even at $\mathrm{pH} \sim 7$, was not sufficiently adsorbed onto the gypsum crystals to inhibit the crystallization process. However, in the presence of $\mathrm{PAA}_{2 \mathrm{~K}}$ at $\mathrm{pH} \sim 4$ and $\sim 7$, the atom $\%$ of $\mathrm{C} 1 \mathrm{~s}$ increased to $\sim 23.8 \%$ and $\sim 25.7 \%$ with $\mathrm{O}$ $\mathrm{C} \mathrm{O}$ peak area of $\sim 18.03 \%$ and $\sim 18.33 \%$ and the $\left.\mathrm{R}_{(\mathrm{O}} \mathrm{C} \mathrm{O} / \mathrm{C} \mathrm{C}\right)$ of $\sim 0.27$ and $\sim 0.40$, respectively. These data reveal the critical role of increasing $\mathrm{pH}$ in deprotonating $\mathrm{PAA}_{2 \mathrm{~K}}$ carboxylate functional groups and consequently increasing the antiscaling efficiency of this additive by enhancing its adsorption affinity on gypsum crystals (also see Figures 1 and 2). In addition, our XPS analysis revealed that the

adsorption of PAA at $\sim 7$ was accompanied by a $\sim 0.5 \mathrm{eV}$ decrease in $\mathrm{O} C \mathrm{O}$ binding energy, which further confirms the surface adsorption of the polymeric additives by bonding onto the gypsum crystals and is similar to that reported for PAA coated hydroxyapatite powders, ${ }^{52}$ and PAA adsorption on alumina. ${ }^{53}$ 


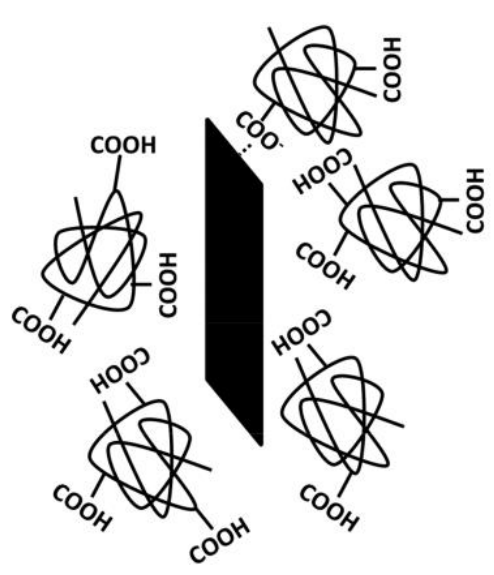

(a)

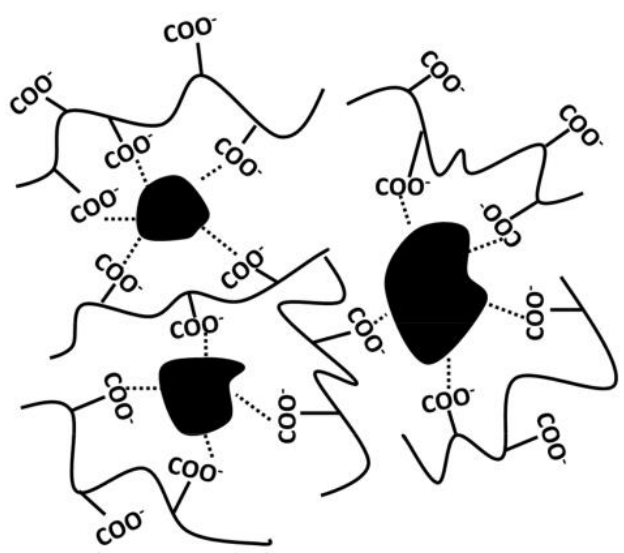

(b)

Figure 7. Schematic showing the change in gypsum microstructure because of PAA2K conformation and its deprotonation: (a) The PAA2K molecules are randomly coiled at $\mathrm{pH} \sim 4$ and had limited adsorption on twin- or needlelike gypsum crystals. (b) Deprotonated PAA2K molecules are in their extended conformation at $\mathrm{pH} \sim 7$, deformed the gypsum crystals, and prevented growth leading to smaller and more isometric crystals (see also Figure 5f).

The data in Tables 1 and 2 reveal that, in the PAA100K system, the atom $\%$ of $\mathrm{C} 1 \mathrm{~s}$ at $\mathrm{pH} \sim 4$ and $\sim 7$ was $\sim 16.6 \%$ and $\sim 15.1 \%$ (with O C O peak area of $\sim 14.07 \%$ and $\sim 8.69 \%, \mathrm{R}--$ of $\sim 0.19$ and $\sim 0.13$, respectively). It can be

$(\mathrm{O} \mathrm{C} \quad \mathrm{O} / \mathrm{C} \mathrm{C})$

seen that both $\mathrm{O} C \mathrm{O}$ peak area and $\mathrm{R}(\mathrm{O}-\mathrm{C} \mathrm{O} / \mathrm{C}-\mathrm{C})$ at $\mathrm{pH} \sim 4$ and $\sim 7$ were lower than the corresponding values obtained for the $\mathrm{PAA}_{2 \mathrm{~K}}$ system. This illustrates the lower adsorption affinity of PAA100K on gypsum crystals in comparison to $\mathrm{PAA}_{2 \mathrm{~K}}$, which resulted in a fast increase in the turbidity of the crystallization solutions when PAA $100 \mathrm{~K}$ was present in the system. In addition, the observed decrease in atom $\%$ of $\mathrm{C}$ 1s and the $\mathrm{O} \mathrm{C} \mathrm{O}$ atom $\%$ when the $\mathrm{pH}$ increased from $\sim 4$ to $\sim 7$ was due to the formation of a "netlike" structure at high $\mathrm{pH}$, which decreased the amount of PAA $100 \mathrm{~K}$ available to be adsorbed on the gypsum crystals.

Here, it is worth noting that we also documented a $\sim 0.6$ $\mathrm{eV}$ decrease in $\mathrm{Ca}^{2+}$ binding energy in the PAA2K modified gypsum crystals when compared to the additive-free crystals (Figure 4). This observation contradicts previously reported data where an increase in $\mathrm{Ca}^{2+}$ binding energy of bassanite and gypsum was observed and interpreted as a consequence of surface adsorption of citric acid ${ }^{54}$ and polycarboxylate. ${ }^{55}$ Although the reason for this discrepancy in $\mathrm{Ca}^{2+}$ binding energy is not clear at this stage, it nevertheless documents a change in the chemical environment of $\mathrm{Ca}^{2+}$ in the formed gypsum crystals because of the surface interactions with the PAA2K.

Finally, one striking observation is the effect that the inhibitors had on the morphology and size of the precipitated gypsum crystals (Figure 5). We ascribe this to the surface adsorption of polymers as has previously been demonstrated for other antiscalants with high surface binding. ${ }^{26}$ The dominant morphology of the gypsum crystals (irregular, large twins; Figure 5a) in the additive-free system was alike to many other previous studies, ${ }^{56,57}$ yet it was different to the needlelike morphology that we have reported in our previous additive-free experiments. ${ }^{30,31}$ This change in shape could be because of the higher supersaturation ( $0.84 \mathrm{vs} 0.55)$ and/or the larger volume of the crystallization solution $\left(1 \mathrm{~L}\right.$ vs $2 \mathrm{~mL}$ ) used in the current study, ${ }^{58}$ yet a full assessment of these two factors on gypsum formation was outside the scope of this study. In the additive containing solutions, $\mathrm{PESA}<1.5 \mathrm{~K}$ did not cause any morphological changes, which was due to the low carboxyl functional groups and lack of surface adsorption on the fast growing gypsum crystals (Figure 5b). Interestingly, morpho-logical changes as a result of adsorption of PESA on calcium oxalate have been previously observed, ${ }^{59}$ but for gypsum this effect was less prominent.

Both PAA $100 \mathrm{~K}$ and $\mathrm{PAA}_{2 \mathrm{~K}}$ when present in solution in a coiled conformation $(\mathrm{pH} \sim 4)$ affected the morphology of the resulting crystals. However, because of higher steric hindrance between coils, the larger molecular weight additive exhibited very limited adsorption, and this resulted in less surface modification (Figure 5c) compared to the effects observed at the same condition with $\mathrm{PAA}_{2 \mathrm{~K}}$ (Figure 5e). At $\mathrm{pH} \sim 7$, the "netlike structure" of PAA $100 \mathrm{~K}$ decreased the availability of monomers for surface adsorption, and thus the morphologies remained almost similar to those in the additive-free system (Figure 5d). In contrast, at $\mathrm{pH} \sim 7$, highly deprotonated PAA2K with a flat configuration was intensely adsorbed, and this led to growth inhibition and resultantly small crystals (Figure 5f). Such tiny crystals are less adhesive to a surface and can therefore be washed away more easily, and thus $\mathrm{PAA}_{2 \mathrm{~K}}$ is a more effective inhibitor and a more effective crystal modifier for gypsum crystallization than PAA100K. Similar gypsum morphology modification in the presence of water-soluble polymers (e.g., 5 ppm acrylic acid-allylpolyethoxy maleic carboxylate) has been reported, ${ }^{60}$ while the adsorption of PAA on other minerals such as barium sulfate ${ }^{61}$ and calcium carbonate $^{62}$ has also led to crystal morphology changes.

For the observed morphologies we have schematically illustrated the effects of $\mathrm{pH}$ on $\mathrm{PAA}_{2} \mathrm{~K}$ conformation and its adsorption in Figure 7.

Although we showed that PESA $<1.5 \mathrm{~K}$ was a less efficient inhibitor, we emphasize that this could probably be due to the higher gypsum supersaturation in this research in comparison to natural fluids where gypsum precipitates (e.g., seawater). However, the potential of both PESA and PASP as promising gypsum antiscalants in industrial plants is well-known, ${ }^{63}$ yet we show here what the mechanism is. Furthermore, we also show the potential of green polycarboxylic inhibitors as more effective and efficient additives and suggest that these should 
replace the nonbiodegradable polycarboxylic inhibitors. Our results also revealed the importance of choosing the correct molecular weight antiscalant and the fact that if green inhibitors like PESA and PASP are to be used in an industrial fluid handling system (where gypsum mineral scaling is a problem) they can substantially retard nucleation and growth even at low concentrations. This is not just because they retard nucleation and growth but is primarily due to the induced morphological effects. Therefore, the green inhibitors will reduce clogging and surface adhesion to production materials.

\section{CONCLUSION}

In this study, we documented the effects that polycarboxylic antiscalants have on the nucleation and growth kinetics of gypsum crystals at $21{ }^{\circ} \mathrm{C}$ and illustrated the potential of biodegradable PASP and PESA to replace the nonbiodegradable PAA additives. A concentration of $20 \mathrm{ppm}$ of additives affected gypsum formation in the order PESA < PAA < PASP. Our data showed that, among the tested additives, PASP completely inhibited gypsum crystallization, while the PAA with low molecular weight, $\mathrm{PAA}_{2 \mathrm{~K}}$, increased the induction time and decreased the crystallization kinetics far more than the PAA with the high molecular weight, $\mathrm{PAA}_{100 \mathrm{~K}}$. This effect was also $\mathrm{pH}$ dependent; with increasing $\mathrm{pH}$ from $\sim 4$ to $\sim 7 \mathrm{a}$ positive effect in the efficiency of the PAA2K was observed, while for PAA $100 \mathrm{~K}$ the opposite was observed, likely due to the conformational changes in the PAA at near neutral $\mathrm{pH}$. Combining our XPS and turbidity results clearly showed that the depletion of additives in the crystallization solution is a result of their surface adsorption, which in turn caused changes in the morphology of the growing gypsum crystals.

\section{AUTHOR INFORMATION}

\section{Corresponding Authors}

*E-mail: t.rabizadeh@tabrizu.ac.ir.

${ }^{\star}$ E-mail: Benning@gfz-potsdam.de.

ORCID (1)

Taher Rabizadeh: 0000-0003-3483-2764

David J. Morgan: 0000-0002-6571-5731

Notes

The authors declare no competing financial interest.

\section{ACKNOWLEDGMENTS}

This study was supported by a Marie Curie grant from the European Commission in the framework of the MINSC ITN (Initial Training Research network), Project number 290040 and the German Helmholtz Recruiting Initiative to L.G.B. The authors would like to thank the Cohen Geochemistry Laboratories in the School of Earth and Environment, University of Leeds, and the Leeds Electron Microscopy and Spectroscopy Centre (LEMAS) for help and access to instruments during the course of this study.

\section{REFERENCES}

(1) MacAdam, J.; Jarvis, P. In Mineral Scales and Deposits: Scientific and Technological Approaches, 1st ed.; Amjad, Z., Demadis, K. D., Eds.; Elsevier: Amsterdam, 2015; Chapter 1, pp 3-47.

(2) Alabi, A.; Chiesa, M.; Garlisi, C.; Palmisano, G. Advances in antiscale magnetic water treatment. Environ. Sci.: Water Res. \& Technol. 2015, 1, 408.

(3) Olajire, A. A. A review of oilfield scale management technology for oil and gas productionm. J. Pet. Sci. Eng. 2015, 135, 723.
(4) Kelland, M. A. Effect of various cations on the formation of calcium carbonate and barium sulfate scale with and without scale inhibitors. Ind. Eng. Chem. Res. 2011, 50, 5852.

(5) Demadis, K. D.; Mavredaki, E.; Somara, M. Additive-driven dissolution enhancement of colloidal silica. 2. Environmentally friendly additives and natural products. Ind. Eng. Chem. Res. 2011, 50, 13866

(6) Kim, M. M.; Au, J.; Rahardianto, A.; Glater, J.; Cohen, Y.; Gerringer, F. W.; Gabelich, C. J. Impact of conventional water treatment coagulants on mineral scaling in RO desalting of brackish water. Ind. Eng. Chem. Res. 2009, 48, 3126.

(7) Prisciandaro, M.; Olivieri, E.; Lancia, A.; Musmarra, D. Gypsum precipitation from an aqueous solution in the presence of nitrilotrimethylenephosphonic acid. Ind. Eng. Chem. Res. 2006, 45, 2070

(8) Adams, J. F.; Papangelakis, V. G. Gypsum scale formation in continuous neutralization reactors. Can. Metall. Q. 2000, 39, 421.

(9) Rahardianto, A. Y.; Shih, W.; Lee, R. W.; Cohen, Y. Diagnostic characterization of gypsum scale formation and control in RO membrane desalination of brackish water. J. Membr. Sci. 2006, 279, 655.

(10) Mi, B.; Elimelech, M. Gypsum scaling and cleaning in forward osmosis: measurements and mechanisms. Environ. Sci. Technol. 2010, 44, 2022.

(11) Freyer, D.; Voigt, W. Crystallization and phase stability of $\mathrm{CaSO}_{4}$ and $\mathrm{CaSO}_{4}$-based salts. Monatsh. Chem. 2003, 134, 693.

(12) Amiri, M.; Moghadasi, J.; Jamialahmadi, M. The Effect of Temperature on Calcium Sulfate Scale Tendency in an Iranian Oil Reservoir and Production Equipment During Water Injection. Energy Sources, Part A 2013, 35, 2264.

(13) Crabtree, M.; Eslinger, D.; Fletcher, P.; Miller, M.; Johnson, A.; King, G. Fighting scale -removal and prevention. Oilfield Rev. 1999, 11 (3), 30.

(14) Hasson, D.; Shemer, H.; Sher, A. State of the art of friendly "green" scale control inhibitors: a review article. Ind. Eng. Chem. Res. 2011, 50, 7601.

(15) Ketrane, R.; Saidani, B.; Gil, O.; Leleyter, L.; Baraud, F. Efficiency of five scale inhibitors on calcium carbonate precipitation from hard water: effect of temperature and concentration. Desalination 2009, 249, 1397.

(16) Li, J.; Zhou, Y.; Yao, Q.; Wang, T.; Zhang, A.; Chen, Y.; Wu, W.; Sun, W. Preparation and Evaluation of a PolyetherBased Polycarboxylate as a Kind of Inhibitor for Water Systems. Ind. Eng. Chem. Res. 2017, 56, 2624.

(17) Du, K.; Zhou, Y.; Wang, L.; Wang, Y. Fluorescent tagged no phosphate and nitrogen free calcium phosphate scale inhibitor for cooling water systems. J. Appl. Polym. Sci. 2009, 113, 1966-1974.

(18) Zhang, Q.; Zhang, Z.; Teng, J.; Huang, H.; Peng, Q.; Jiao, T.; Hou, L.; Li, B. Highly efficient phosphate sequestration in aqueous solutions using nanomagnesium hydroxide modified polystyrene materials. Ind. Eng. Chem. Res. 2015, 54, 2940.

(19) Withers, P. J.; Elser, J. J.; Hilton, J.; Ohtake, H.; Schipper, W. J.; van Dijk, K. C. Greening the global phosphorus cycle: how green chemistry can help achieve planetary $\mathrm{P}$ sustainability. Green Chem. 2015, 17, 2087.

(20) Belarbi, Z.; Gamby, J.; Makhloufi, L.; Sotta, B.; Tribollet, B. Inhibition of calcium carbonate precipitation by aqueous extract of Paronychia argentea. J. Cryst. Growth 2014, 386, 208.

(21) Jessop, P.; Ahmadpour, F.; Buczynski, M.; Burns, T.; Green Ii, N.; Korwin, R.; Long, D.; Massad, S.; Manley, J.; Omidbakhsh, N. Opportunities for greener alternatives in chemical formulations. Green Chem. 2015, 17, 2664.

(22) Liu, D.; Dong, W.; Li, F.; Hui, F.; Ledion, J. Comparative performance of polyepoxysuccinic acid and polyaspartic acid on scaling inhibition by static and rapid controlled precipitation methods. Desalination 2012, 304, 1.

(23) Gao, Y.; Fan, L.; Ward, L.; Liu, Z. Synthesis of polyaspartic acid derivative and evaluation of its corrosion and scale inhibition performance in seawater utilization. Desalination 2015, 365, 220. 
(24) Prisciandaro, M.; Santucci, A.; Lancia, A.; Musmarra, D. Role of citric acid in delaying gypsum precipitation. Can. J. Chem. Eng. 2005, 83, 586.

(25) Senthilmurugan, B.; Ghosh, B.; Kundu, S. S.; Haroun, M.; Kameshwari, B. Maleic acid based scale inhibitors for calcium sulfate scale inhibition in high temperature application. J. Pet. Sci. Eng. 2010, 75, 189.

(26) Ling, L.; Zhou, Y.; Huang, J.; Yao, Q.; Liu, G.; Zhang, P.; Sun, W.; Wu, W. Carboxylate-terminated double-hydrophilic block copolymer as an effective and environmental inhibitor in cooling water systems. Desalination 2012, 304, 33.

(27) Amjad, Z.; Koutsoukos, P. G. Evaluation of maleic acid based polymers as scale inhibitors and dispersants for industrial water applications. Desalination 2014, 335, 55.

(28) Parkhurst, D. L.; Appelo, C. A. J. In U.S. Geological Survey Techniques and Methods; USGS: Reston, VA, 2013; Book 6, Chapter A43, p 497; http://pubs.usgs.gov/tm/06/a43/.

(29) Abramoff, M. D.; Magalhaes, P. J.; Ram, S. J. Image Processing with ImageJ. Biophotonics Inter. 2004, 11, 36.

(30) Rabizadeh, T.; Peacock, C. L.; Benning, L. G. Carboxylic acids: effective inhibitors for calcium sulfate precipitation? Mineral. Mag. 2014, 78, 1465.

(31) Rabizadeh, T.; Stawski, T. M.; Morgan, D. J.; Peacock, C. L.; Benning, L. G. The effects of inorganic additives on the nucleation and growth kinetics of calcium sulfate dihydrate crystals. Cryst. Growth Des. 2017, 17, 582.

(32) Kokufuta, E.; Suzuki, S.; Harada, K. Potentiometric titration behavior of polyaspartic acid prepared by thermal polycondensation.

BioSystems 1977, 9, 211.

(33) Zhang, L.; Zhu, Z.; Qiu, Y.; Zhang, R.; Zhao, J. Determination of the dissociation constants of polyepoxysuccinic acid. Front. Environ. Sci. Eng. China 2008, 2, 505.

(34) De Giglio, E.; Cometa, S.; Cioffi, N.; Torsi, L.; Sabbatini, L. Analytical investigations of poly (acrylic acid) coatings electro-deposited on titanium-based implants: a versatile approach to biocompatibility enhancement. Anal. Bioanal. Chem. 2007, 389, 2055.

(35) Lioliou, M. G.; Paraskeva, C. A.; Koutsoukos, P. G.; Payatakes, A. C. Calcium sulfate precipitation in the presence of water-soluble polymers. J. Colloid Interface Sci. 2006, 303, 164.

(36) Sun, X.; Zhang, J.; Yin, C.; Zhang, J.; Han, J. Poly (aspartic acid)-tryptophan grafted copolymer and its scale inhibition perform-ance. J. Appl. Polym. Sci. 2015, 132, 1.

(37) Wang, H.; Liu, G.; Huang, J.; Zhou, Y.; Yao, Q.; Ma, S.; Cao, K.; Liu, Y.; Wu, W.; Sun, W. Performance of an environmentally friendly anti-scalant in $\mathrm{CaSO}_{4}$ scale inhibition. Desalin. Water Treat.

$2015,53,8$.

(38) Mountrichas, G.; Pispas, S. Synthesis and $\mathrm{pH}$ responsive self-assembly of new double hydrophilic block copolymers. Macro-molecules 2006, 39, 4767.

(39) Grunlan, J. C.; Liu, L.; Kim, Y. S. Tunable single-walled carbon nanotube microstructure in the liquid and solid states using poly (acrylic acid). Nano Lett. 2006, 6, 911.

(40) Rianasari, I.; Benyettou, F.; Sharma, S. K.; Blanton, T.; Kirmizialtin, S.; Jagannathan, R. A Chemical Template for Synthesis of Molecular Sheets of Calcium Carbonate. Sci. Rep. 2016, 6, 2832.

(41) Wan, L. Q.; Jiang, J.; Arnold, D. E.; Guo, X. E.; Lu, H. H.; Mow, V. C. Calcium concentration effects on the mechanical and biochemical properties of chondrocyte-alginate constructs. Cell. Mol. Bioeng. 2008, 1, 93.

(42) Laguecir, A.; Ulrich, S.; Labille, J.; Fatin-Rouge, N.; Stoll, S.; Buffle, J. Size and $\mathrm{pH}$ effect on electrical and conformational behavior of poly (acrylic acid): simulation and experiment. Eur. Polym. J. 2006, 42, 1135.

(43) Liufu, S.; Xiao, H.; Li, Y. Adsorption of poly (acrylic acid) onto the surface of titanium dioxide and the colloidal stability of aqueous suspension. J. Colloid Interface Sci. 2005, 281, 155.

(44) Weijnen, M.; Van Rosmalen, G. Adsorption of phosphonates on gypsum crystals. J. Cryst. Growth 1986, 79, 157.
(45) Weijnen, M. P. C.; Van Rosmalen, G. M.; Van der Leeden, M. C. In Proc., Intl. Meeting of Geochemistry of Earth Surface and Mineral Formation, 1st ed.; Rodriguez, R., Thardy, Y., Eds.; CSIC-CSIC Press: Madrid, 1987; p 753.

(46) Zhang, G.; Yu, T. In Chemistry of Variable Charge Soils, 1st ed.; Yu, T. R.; Oxford Univ. Press: New York, 1997; Chapter 6, p 175.

(47) Zarbakhsh, A.; Lee, S.; Welbourn, R.; Clarke, S.; Skoda, M.; Clifton, L. Adsorption of sodium hexanoate on $\alpha$-alumina. J. Colloid Interface Sci. 2013, 407, 348.

(48) Ni, X.; Liu, Q. The adsorption and configuration of octyl hydroxamic acid on pyrochlore and calcite. Colloids Surf., A 2012, 411, 80.

(49) Yoshida, Y.; Van Meerbeek, B.; Nakayama, Y.; Yoshioka, M.; Snauwaert, J.; Abe, Y.; Lambrechts, P.; Vanherle, G.; Okazaki, M. Adhesion to and decalcification of hydroxyapatite by carboxylic acids. J. Dent. Res. 2001, 80, 1565.

(50) Zhang, S.; Gonsalves, K. E. Influence of the chitosan surface profile on the nucleation and growth of calcium carbonate films. Langmuir 1998, 14, 6761.

(51) Greczynski, G.; Hultman, L. C 1s Peak of Adventitious Carbon Aligns to the Vacuum Level: Dire Consequences for Material's Bonding Assignment by Photoelectron Spectroscopy. ChemPhysChem 2017, 18, 1507.

(52) Shen, D.; Fang, L.; Chen, X.; Tang, Y. Structure and properties of polyacrylic acid modified hydroxyapatite/liquid crystal polymer composite. J. Reinf. Plast. Compos. 2011, 30, 1155.

(53) Zhu, H.; Chen, Z.; Sheng, Y.; Luong Thi, T. T. L. Flaky polyacrylic acid/aluminium composite particles prepared using insitu polymerization. Dyes Pigm. 2010, 86, 155.

(54) Mao, J.; Jiang, G.; Chen, Q.; Guan, B. Influences of citric acid on the metastability of $\alpha$-calcium sulfate hemihydrate in $\mathrm{CaCl} 2$ solution. Colloids Surf., A 2014, 443, 265.

(55) Guan, B.; Ye, Q.; Zhang, J.; Lou, W.; Wu, Z. Interaction between $\alpha$-calcium sulfate hemihydrate and superplasticizer from the point of adsorption characteristics, hydration and hardening process.

Cem. Concr. Res. 2010, 40, 253.

(56) Rubbo, M.; Bruno, M.; Massaro, F. R.; Aquilano, D. The five twin laws of gypsum $\left(\mathrm{CaSO}_{4} \cdot 2 \mathrm{H}_{2} \mathrm{O}\right)$ : a theoretical comparison of the interfaces of the contact twins. Cryst. Growth Des. 2012, 12, 264.

(57) Ruiz-Agudo, E.; Alvarez-Lloret, P.; Ibanez-Velasco, A.; Ortega-Huertas, M. Crystallographic Control in the Replacement of Calcite by Calcium Sulfates. Cryst. Growth Des. 2016, 16, 4950.

(58) Rabizadeh, T. The nucleation, growth kinetics and mechanism of sulfate scale minerals in the presence and absence of additives as inhibitors. Ph.D. Thesis, University of Leeds, Leeds, December 2016. (59) Zhang, Y.; Tang, Y.; Xu, J.; Zhang, D.; Lu, G.; Jing, W. Modulation of polyepoxysuccinic acid on crystallization of calcium oxalate. J. Solid State Chem. 2015, 231, 7.

(60) Cao, K.; Zhou, Y.; Liu, G.; Wang, H.; Sun, W. Preparation and properties of a polyether based polycarboxylate as an antiscalant for gypsum. J. Appl. Polym. Sci. 2014, 131, 1.

(61) Li, J.; Liu, D.; Jiang, H.; Wang, J.; Jing, X.; Chen, R.; Zhu, W.; Han, $\mathrm{S}$.; Li, W.; Wei, H. Effects of polyacrylic acid additive on barium sulfate particle morphology. Mater. Chem. Phys. 2016, 175, 180.

(62) Ouhenia, S.; Chateigner, D.; Belkhir, M.; Guilmeau, E.; Krauss, C. Synthesis of calcium carbonate polymorphs in the presence of polyacrylic acid. J. Cryst. Growth 2008, 310, 2832.

(63) Sun, Y.; Xiang, W.; Wang, Y. Study on polyepoxysuccinic acid reverse osmosis scale inhibitor. J. Environ. Sci. 2009, 21, 73. 